\title{
Commentary: When the back of the envelope calculation just isn't good enough, use decision analysis modeling
}

\author{
Derrick Y. Tam, MD, ${ }^{\mathrm{a}, \mathrm{b}}$ and Mario Gaudino, MD
}

\footnotetext{
From the ${ }^{\mathrm{a}}$ Division of Cardiac Surgery, Department of Surgery, Schulich Heart Centre, Sunnybrook Health Sciences Centre and ${ }^{\mathrm{b}}$ Institute of Health Policy, Management and Evaluation, University of Toronto, Toronto, Canada; and ${ }^{\mathrm{c}}$ Department of Cardiothoracic Surgery, Weill Cornell Medicine, New York, NY.

Disclosures: Dr Tam is supported by a Canadian Institutes of Health Research Fellowship (Canada). Dr Gaudino has nothing to disclose with regard to commercial support.

Received for publication June 19, 2019; accepted for publication June 20, 2019; available ahead of print Aug 9, 2019.

Address for reprints: Mario Gaudino, MD, Department of Cardiothoracic Surgery, Weill Cornell Medicine, 525 East 68th St, New York, NY 10065 (E-mail: mfg9004@med.cornell.edu).

J Thorac Cardiovasc Surg 2020;159:2243-4

$0022-5223 / \$ 36.00$

Copyright (C) 2019 by The American Association for Thoracic Surgery

https://doi.org/10.1016/j.jtcvs.2019.06.094
}

As surgeons, we make "back of the envelope" calculations on a daily basis in deciding the optimal treatment for our patients. We consider patient characteristics, clinical factors, and our own expertise and experience, and perform a quick mental calculation as to whether the patient would benefit from a certain procedure. However, these calculations can become quickly complicated in areas that are more controversial or in situations that require the balancing of multiple risks and benefits to prognosticate and project a lifetime of benefit for the patient. One such clinical decision that may require a more sophisticated method to measure the trade-offs of the risks and benefits of a procedure is in the management of moderate ischemic mitral regurgitation (MR) at the time of coronary artery bypass grafting $(\mathrm{CABG})$. In the Cardiothoracic Surgical Trials Network (CTSN) randomized clinical trial comparing CABG with $\mathrm{CABG}$ and mitral valve repair in patients with chronic, moderate, ischemic MR, there was a reduction in moderate or severe MR with adjunctive repair but also increased neurologic events and supraventricular arrhythmias. ${ }^{1,2}$ In this scenario, it becomes more difficult to decide whether this treatment would be beneficial to our patient. Decision analysis consists of a suite of techniques and tools that allow for analyses that account for events over time from a variety of data sources to estimate the impact of an intervention on valued health outcomes and includes tools for cost-effectiveness analysis. ${ }^{3}$

In this issue of the Journal, Ferket and colleagues ${ }^{4}$ conducted a cost-effectiveness analysis comparing CABG with $\mathrm{CABG}$ with mitral valve repair for chronic ischemic MR using trial data from the CTSN randomized clinical trial. Their analysis showed that index hospitalization costs were higher with $\mathrm{CABG}$ and mitral valve repair, yet the incremental gain in quality-adjusted life-years (QALYs) was similar between the 2 treatments. This led to an estimated incremental cost-effectiveness ratio (ICER) more than \$300,000/QALY. As a reference, American

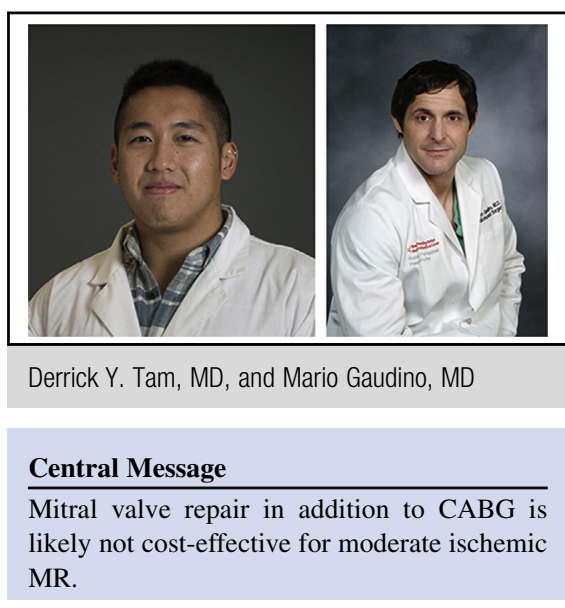

See Article page 2230.

College of Cardiology/American Heart Association costing methodology guidelines consider interventions with ICERs less than \$50,000/QALY to be of high value and more than $\$ 150,000 / \mathrm{QALY}$ to be of low value. ${ }^{5}$ For this treatment, the probability that $\mathrm{CABG}$ plus mitral valve repair would be cost-effective over a 10-year time horizon was less than $37 \%$ at a willingness-to-pay threshold of $\$ 100,000 /$ QALY (the intermediate value threshold). In their sensitivity analysis, the authors concluded that mitral valve repair in chronic ischemic MR may be cost-effective only if it improved late survival. This suggests that the higher ICER and overall lack of cost-effectiveness are the result of a lack of differences in effectiveness (ie, the denominator) and not costs (ie, the numerator) in the ICER. Ferket and colleagues ${ }^{4}$ are to be congratulated for using sophisticated microsimulation modeling techniques to realistically and accurately model the disease state of chronic ischemic MR. The authors used a fully probabilistic model to address uncertainty in input parameters and performed various sensitivity analyses, which is key when the model inputs are obtained from a small clinical trial.

However, although decision analysis and costeffectiveness analysis may be the ideal tools to address their research questions, limitations still exist. The input for this model was obtained from the CTSN trials, and as such, these results may not be generalizable outside of a clinical trial setting. Furthermore, results from CTSN were limited to 2 years, and as such, the authors had to extrapolate and make assumptions regarding long-term survival and events, adding additional uncertainty in their modeling. Although 
this economic evaluation is clear that mitral valve repair and CABG are likely not cost-effective in this overall population, there may still be selected patients who would benefit tremendously from the procedure. This cost-effectiveness analysis cannot be used to address who those individuals are. Finally, there are the usual controversies and concerns surrounding cost-effectiveness analysis. The use of QALYs remains a hotly debated topic in cost-effectiveness research, ${ }^{6}$ and the use of thresholds described in the American College of Cardiology/American Heart Association cost methodology article may not be appropriate for all healthcare systems. ${ }^{7}$

Despite these limitations, the authors should be applauded for addressing this important issue in health policy. As healthcare spending continues to grow around the world, understanding the cost and effectiveness of our everyday procedures becomes critically important to ensure equitable and timely access to care. In this carefully conducted analyses, Ferket and colleagues ${ }^{4}$ highlight the sophisticated tools that are available to perfect and confirm our clinical gestalt and back of the envelope calculations that we perform on a daily basis.

\section{References}

1. Smith PK, Puskas JD, Ascheim DD, Voisine P, Gelijns AC, Moskowitz AJ, et al; Cardiothoracic Surgical Trials Network Investigators. Surgical treatment of moderate ischemic mitral regurgitation. N Engl J Med. 2014;371:2178-88.

2. Michler RE, Smith PK, Parides MK, Ailawadi G, Thourani V, Moskowitz AJ, et al; CTSN. Two-year outcomes of surgical treatment of moderate ischemic mitral regurgitation. N Engl J Med. 2016;374:1932-41.

3. Weinstein MC, O’Brien B, Hornberger J, Jackson J, Johannesson M, McCabe C, et al; ISPOR Task Force on Good Research Practices-Modeling Studies. Principles of good practice for decision analytic modeling in health-care evaluation: report of the ISPOR Task Force on Good Research PracticesModeling Studies. Value Health. 2003;6:9-17.

4. Ferket BS, Thourani VH, Voisine P, Hohmann SF, Chang HL, Smith PK, et al; CTSN Investigators. Cost-effectiveness of coronary artery bypass grafting plus mitral valve repair versus coronary artery bypass grafting alone for moderate ischemic mitral regurgitation. J Thorac Cardiovasc Surg. 2020; 159:2230-40.e15.

5. Anderson JL, Heidenreich PA, Barnett PG, Creager MA, Fonarow GC, Gibbons RJ, et al; ACC/AHA Task Force on Performance Measures; ACC/AHA Task Force on Practice Guidelines. ACC/AHA statement on cost/value methodology in clinical practice guidelines and performance measures: a report of the American College of Cardiology/American Heart Association task force on performance measures and task force on practice guidelines. Circulation. 2014; 129:2329-45.

6. McGregor M, Caro JJ. QALYs: are they helpful to decision makers? Pharmacoeconomics. 2006;24:947-52.

7. Hirth RA, Chernew ME, Miller E, Fendrick AM, Weissert WG. Willingness to pay for a quality-adjusted life year: in search of a standard. Med Decis Making. 2000; 20:332-42. 